\title{
ПОДХОДЫ К РАЗВИТИЮ ПРЕДПРИНИМАТЕЛЬСТВА В УСЛОВИЯХ ПАНДЕМИИ (НА ПРИМЕРЕ СФЕРЫ ТУРИЗМА)
}

\section{APPROACHES TO THE DEVELOPMENT OF ENTREPRENEURSHIP IN THE CONDITIONS OF THE PANDEMIC (ON THE EXAMPLE OF THE SPHERE OF TOURISM) \\ E. Ksenofontova}

Summary: In the context of the coronavirus pandemic and a decrease in the real disposable income of the population of the Russian Federation, stimulating the demand for travel to Russian resorts is extremely relevant. In order to increase the occupancy of Russian resorts and hotels during the difficult period of the pandemic, in order to preserve jobs and create an effective mechanism for supporting consumers, it is necessary to expand the opportunities for citizens of the Russian Federation to travel and recover at Russian resorts. New measures of state support have been introduced for the enterprises of the hotel and tourism industry in Russia, which have found themselves in a collapse due to the coronavirus.

Keywords: tourism industry, cashback, hospitality, competencies, Russian resorts, hotel brand, coronavirus pandemic.
B связи с сокращением доходов туротрасли Ростуризму совместно с представителями экспертных и предпринимательских сообществ необходимо определить новые меры поддержки. По мнению экспертного сообщества, туриндустрия России предлагает достаточно качественные услуги. Программа возврата кэшбека туристам за купленные туры помогает расширить границы высокого сезона и осваивать новые туристические направления.

В рамках творческого конкурса «Мастера гостеприимства» платформы «Россия - страна возможностей» было определено, что в России существует необходимость формирования у обучающихся ВУЗов новых управленческих компетенций и навыков проектного управления. Также, необходимо создание коммуникационной площадки для обмена опытом и содействия раскрытию предпринимательского потенциала у начинающих, в том числе в образовательных программах нужно предусмотреть внедрение технологических новаций и программного обеспечения в туристской сфере.

В индустрии гостеприимства оказание услуги требует присутствия и поставщика, и потребителя. Поэтому персонал, непосредственно контактирующий с клиентом, является частью оказываемой услуги. Как показывает практика, даже если уровень качества блюд в ресторане
Ксенофонтова Екатерина Андреевна

соискатель, ФГБОУВО «Санкт-Петербургский государственный экономический университет» tyuksenofontova@mail.ru

Аннотация: В условиях пандемии коронавируса и снижения реально располагаемых доходов населения РФ стимулирование спроса на поездки по российским курортам является исключительно актуальным. С целью повышения загрузки российских курортов и гостиниц в трудный период пандемии для сохранения рабочих мест и создания эффективного механизма поддержки потребителей необходимо расширять возможности путешествовать и оздоравливаться на российских курортах гражданам РФ. Для предприятий гостинично-туристической отрасли России, оказавшихся в коллапсе из-за коронавируса, введены новые меры государственной поддержки.

Ключевые слова: туротрасль, кэшбэк, гостеприимство, компетенции, российские курорты, гостиничный бренд, пандемия коронавируса.

высокий, обслуживание потребителя может отрицательным образом сказаться на восприятии от всей поездки на курорт. То есть необходимо разрабатывать и внедрять системы управления качеством услуг в избранной профессиональной сфере

Падение объема продаж в туротрасли достигало уровня 90\%, а ее доходы в первом полугодии 2020 года сократились более чем на 1,5 трлн рублей.

Для поддержания уровня качества бренда необходимо разрабатывать и внедрять маркетинговые стратегии и программы в туристской сфере.

Основной причиной «невнимания» к маркетинговой деятельности в туристическом бизнесе выделяют:

- уровень маркетинговой подготовки управленцев;

- непонимание ценности маркетинга, стремление в условиях пандемии коронавируса сэкономить на финансировании маркетинговых программ;

- недостаточное информирование потребителя о специфике услуги;

- нечеткое позиционирование бренда, «отпугивающее» потенциальных потребителей туристических услуг.

Показатели распределения продаж туров на черно- 
морские курорты Краснодарского края и Крыма в сезоне 2019 г и распределения продаж туров на курорты России после месяца активных продаж в сезоне 2020 г представлены на рис. 1 и 2.

В опросе, проводившемся в группе портала в соцсети "ВКонтакте" и в Telegram, приняло участие более 4,5 тысячи и 11,2 тысячи пользователей соответственно. Участникам предлагалось выбрать несколько вариантов мест, где они хотели бы отдохнуть. В список вошли Москва, Санкт-Петербург, Черное море, Алтай, Камчатка, Магадан, Якутия, Карелия и Северный Кавказ. Также можно было выбрать вариант "другое". Больше всего проголосовали за Алтай (24-36\% в зависимости от площадки).
Подписчики "ВКонтакте", помимо отдыха на Алтае, хотели бы посетить Санкт-Петербург и Черное море. А пользователи Telegram выразили желание побывать на Камчатке (35\%) и в Карелии (28\%). Российский туризм можно назвать конкурентоспособным: к примеру, с открытием чартерной программы в Хакасию билеты тудаобратно будут стоить 18 тысяч рублей вместо 38. Распределение продаж туров на курорты России по регионам и сегментам туров представлено на рисунке 3

В настоящее время проблема управления качеством туристических услуг активно обсуждается научным сообществом. Наибольшее внимание уделяется безопасности клиентов и обучению персонала туристического

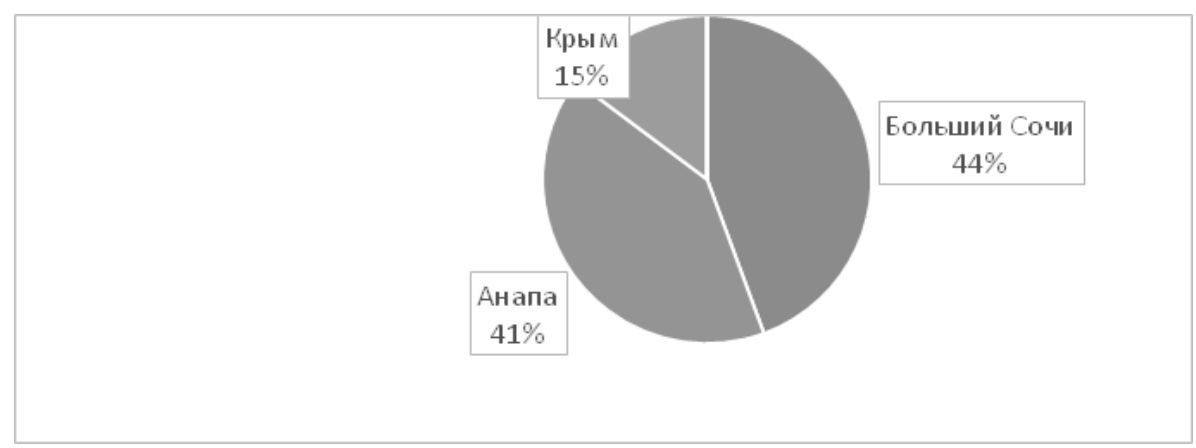

Рис. 1. Распределение продаж туров на черноморские курорты Краснодарского края и Крыма в сезоне 2019 г

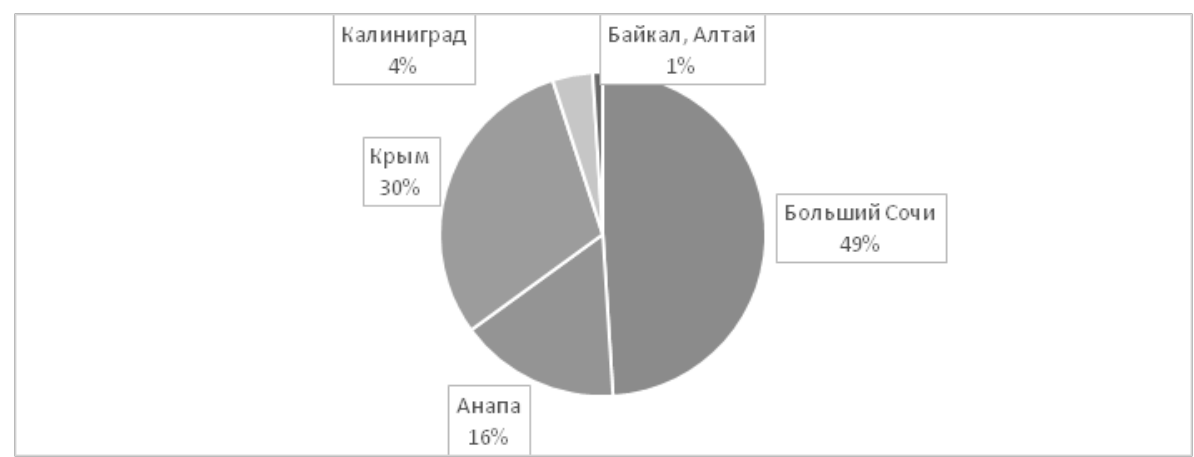

Рис. 2. Распределение продаж туров на курорты России после месяца активных продаж в сезоне 2020 г

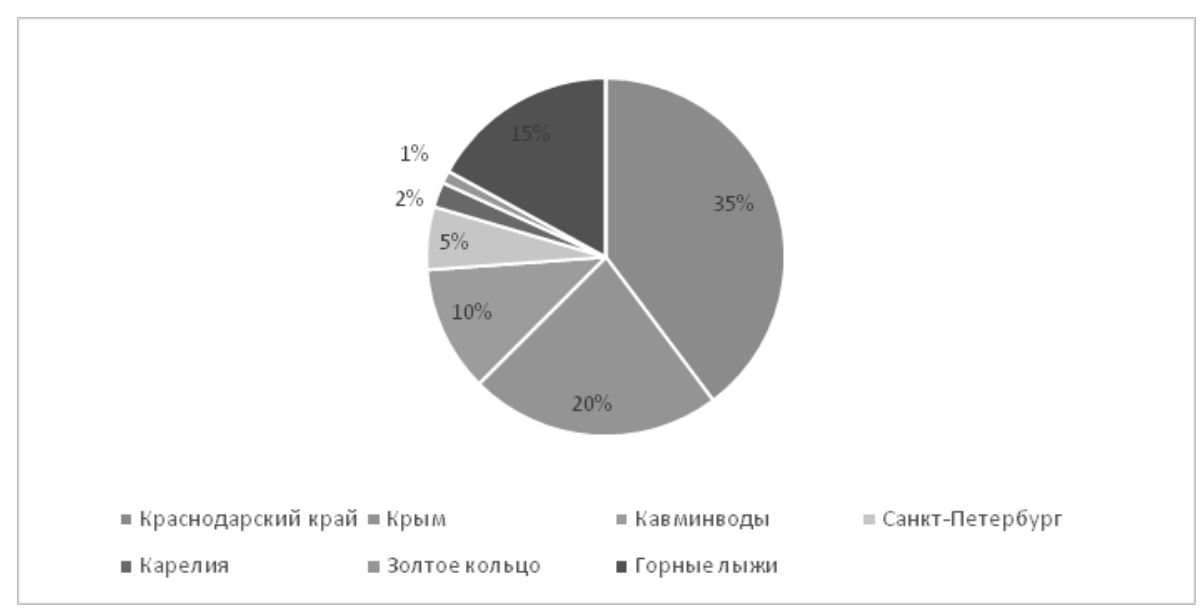

Рис. 3. Распределение продаж туров на курорты России по регионам и сегментам туров. 
предприятия. Однако некоторые вопросы требуют более глубокого изучения. Одним из таких вопросов является организация системы менеджмента качества в туристическом предприятии.

Формирование системы менеджмента качества любого туристического предприятия основывается на принципах современного сервиса, представленных на рисунке 4.

Для соответствия качества предоставляемых услуг требованиям потребителей в организации должны быть разработаны стандартизированные правила обслуживания, изучение которых обязательно для персонала. Таким образом, при стандартизации порядка оказания услуг появляется возможность для объективной оценки соответствия оказанной услуги требованиям, заданным потребителем. Однако критерии, по которым будет разрабатываться стандартная процедура обслуживания, а затем проводиться ее оценка, необходимо устанавли- вать с учетом предпочтений потребителей, выявленных с помощью маркетингового исследования.

Маркетинговые исследования - это ключевой инструмент, с помощью которого туристические предприятия могут поддерживать уровень качества обслуживания на конкурентоспособном уровне. Маркетинговые исследования позволяют изучить ожидания клиентов от оказываемой им услуги и определить операции, необходимые для удовлетворения потребителя. Кроме того, маркетинг необходим для организации каналов связи с потребителем с целью оперативного взаимодействия со службой сервиса, учета степени удовлетворенности потребителя обслуживанием туристического предприятия.

Однако предпочтения потребителей имеют тенденцию к постоянному изменению. Для того, чтобы удержать старых клиентов, компании необходимо не только поддерживать качество обслуживания на хорошем

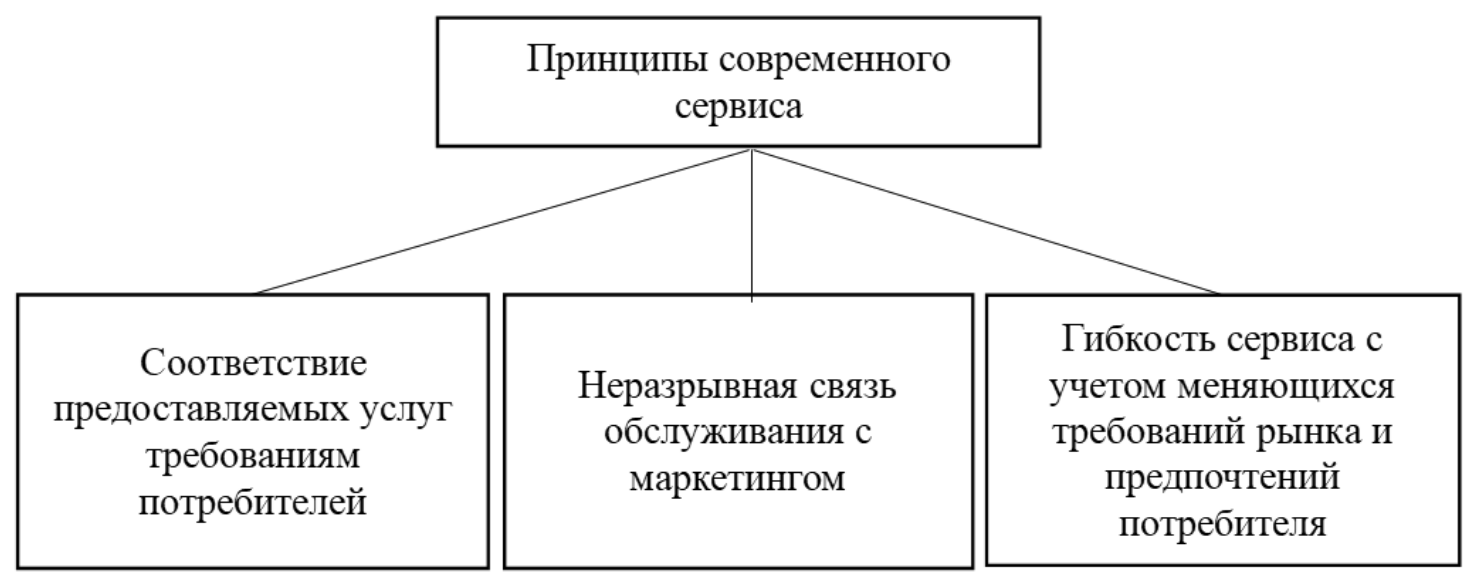

Рис. 4. Основные принципы современного сервиса

\begin{tabular}{|c|c|}
\hline $\begin{array}{l}\text { Информационный } \\
\text { комфорт }\end{array}$ & $\begin{array}{l}\text { •Наличие у обслуживающего персонала всей } \\
\text { необходимой информации относительно тура, } \\
\text { которая может заинтересовать потребителя }\end{array}$ \\
\hline $\begin{array}{l}\text { Экономический } \\
\text { комфорт }\end{array}$ & $\begin{array}{l}\text { •Удобство расчетов для гостей, система скидок, } \\
\text { бонусов, клубные карты и другие меры, } \\
\text { призывающие мотивировать гостя к повторному } \\
\text { выбору заведения размещения, турагенства и др. }\end{array}$ \\
\hline $\begin{array}{l}\text { Эстетический } \\
\text { комфорт }\end{array}$ & $\begin{array}{l}\text { • Эстетично оформленный интерьер предприятия, } \\
\text { который создает ощущение уюта для клиента }\end{array}$ \\
\hline Бытовой комфорт & $\begin{array}{l}\text { •Создание нормальных условий для пребывания гостя } \\
\text { (оптимальная температура, влажность воздуха, } \\
\text { удобство мебели и т.д.) }\end{array}$ \\
\hline $\begin{array}{l}\text { Психологический } \\
\text { комфорт }\end{array}$ & 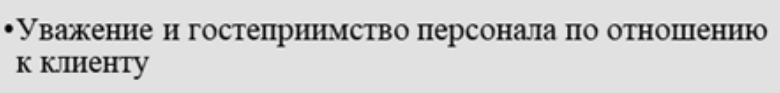 \\
\hline
\end{tabular}

Рис. 5. Основные составляющие комфорта клиента 
уровне, но и предвосхищать ожидания потребителя, чтобы он вновь воспользовался ее услугами. Для привлечения новых клиентов компания должна дифференцировать спектр своих услуг на основе маркетинговых исследований, персонализируя сервис, оставляя при этом стандартные процедуры, которые будут одинаково качественно выполняться для любого клиента.

Организация системы менеджмента качества туристического предприятия будет наиболее эффективной, если все процессы, реализуемые на предприятии, будут описаны согласно требованиям международного стандарта ISO 9001 «Quality management systems - Requirements» или его российского национального аналога ГОСТ Р ИСО 9001 «Системы менеджмента качества. Требования». Такой подход обеспечит стандартизацию не только процедур обслуживания, но также системы управления персоналом и условий для его работы.

На основе результатов маркетинговых исследований формируются потребности клиентов различных сегментов, которые затем используются для разработки требований к качеству сервиса. К примеру, в зависимости от цели поездки клиента (деловая или туристическая) и его уровня потребности в комфорте определяется набор услуг, которые будут способствовать максимальному удовлетворению клиента.

Важно понимать, что руководство организации должно обеспечить внимание персонала к тем ценностям, которые клиент закладывает в получение той или иной услуги. Так как потребитель пользуется только результатом деятельности компании, который зачастую не имеет физической формы, он может оценить качество оказанной ему услуги только по уровню комфорта, испытанного в процессе. Комфорт потребителя складывается из нескольких составляющих, которые имеют различную степень важности для каждого индивида (рис. 5) [2].

Создание комфортных условий для клиента подразумевает собой обеспечение наиболее качественного сервиса по каждой категории. После определения того, насколько полно туристическое предприятие может обеспечить комфорт потребителя, можно разрабатывать стандартизированные процедуры процессов и систему требований к персоналу. Руководитель туристического предприятия должен донести до сотрудников, что оценка качества их работы проводится, в первую очередь, непосредственно потребителем в зависимости от его ценностей и ожиданий, в результате чего персонал сможет самостоятельно оценивать качество оказанной услуги и мотивировать себя на улучшение своей деятельности [1].

Стандартизация процессов представляет собой разработку документированных процедур, описывающих входы, выходы процесса, действия, выполняемые в ходе него, а также ответственных исполнителей. Описаны должны быть следующие процессы:

- взаимодействие между различными уровнями и структурами, касающееся системы управления качества и ее эффективности,

- управление документацией,

- анализ процессов со стороны руководства,

- действия, осуществляемые по результатам анализа со стороны руководства.

Среда организации, в которой работники осуществляют обслуживание клиентов, наиболее важна для туристических предприятий, по сравнению с предприятиями других сфер деятельности. От того, насколько руководство предприятия обеспечит понимание важ-

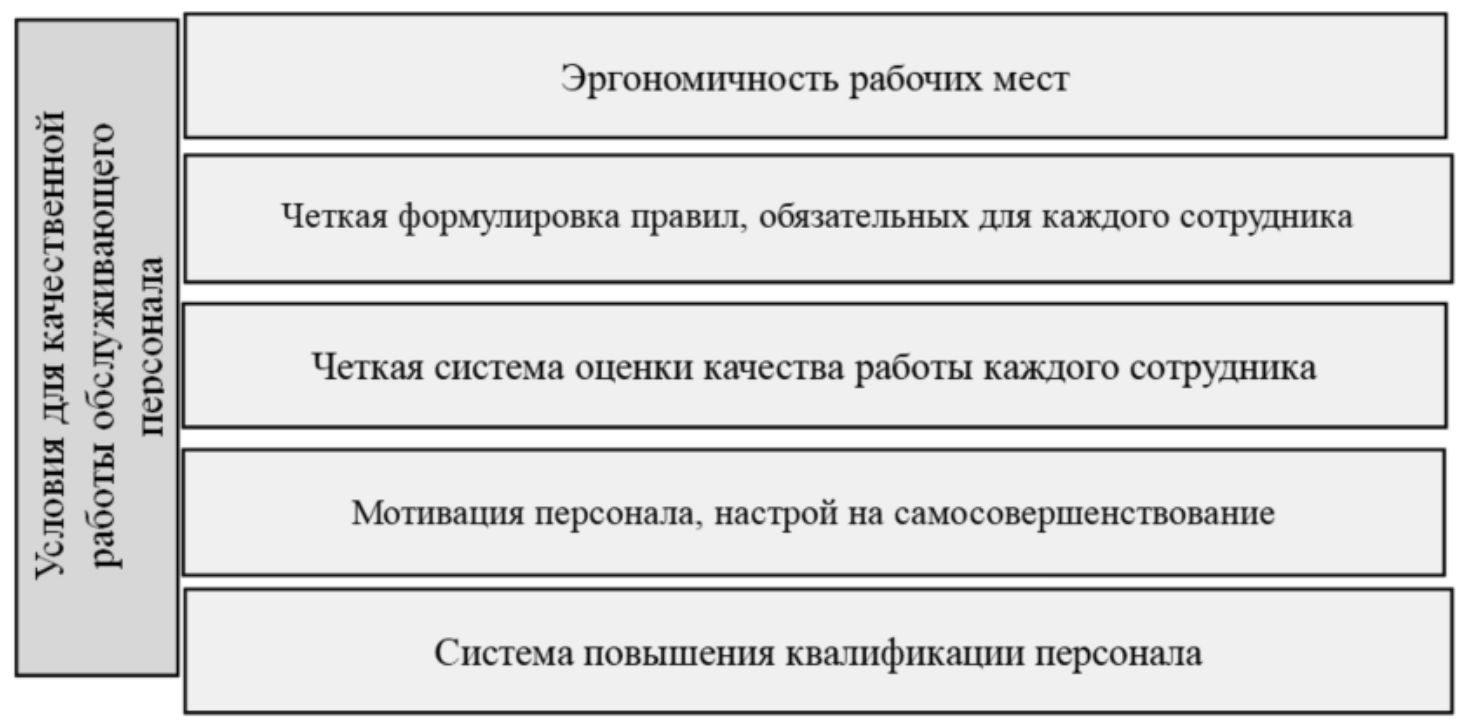

Рис. 6. Необходимые условия для качественной работы персонала 
ности работы подчиненными, а также условия, в которых они работают, зависит качество оказания услуг потребителям. Требования к условиям, необходимым для качественной работы персонала туристической организации, представлены на рисунке 6.

Таким образом, своевременное обеспечение рабочих мест работников всеми необходимыми средствами, стандартизация процессов обслуживания, установление критериев для оценки качества работы персонала, его мотивация и обучение будут способствовать постоянному улучшению качества сервиса туристического предприятия [3].

Система контроля качества оказания услуг туристическим предприятием имеет неразрывную связь с мотивацией и стимулированием персонала, однако в ней есть свои особенности (табл. 1).

Таблица 1.

Составляющие контроля качества сервиса

\begin{tabular}{|c|c|c|}
\hline \multicolumn{3}{|c|}{ Элементы системы контроля качества сервиса } \\
\hline $\begin{array}{c}\text { Непосредственное } \\
\text { касте гостя в оценке } \\
\text { качтва }\end{array}$ & $\begin{array}{c}\text { Постоянная работа } \\
\text { групп по качеству }\end{array}$ & $\begin{array}{c}\text { Применение техниче- } \\
\text { ских средств контроля } \\
\text { качества }\end{array}$ \\
\hline $\begin{array}{c}\text { Создание методик } \\
\text { иритериев оценки } \\
\text { соответстия обслужи- } \\
\text { вания требованиям } \\
\text { стандартов }\end{array}$ & $\begin{array}{c}\text { Четко сформулиро- } \\
\text { ваные качественные } \\
\text { критерии оценки } \\
\text { качества услуг }\end{array}$ & $\begin{array}{c}\text { Создание служб кон- } \\
\text { троля качества услуг } \\
\text { изазиедставителей } \\
\text { лений предприятия }\end{array}$ \\
\hline $\begin{array}{c}\text { создание системы } \\
\text { самоконтроля обслу- } \\
\text { живающего персонала }\end{array}$ & $\begin{array}{c}\text { Участие персонала } \\
\text { в создании систем } \\
\text { критериев оценки } \\
\text { качества }\end{array}$ & $\begin{array}{c}\text { Проведение неза- } \\
\text { висимой экспертизы } \\
\text { качества услуг }\end{array}$ \\
\hline
\end{tabular}

Наиболее важными элементами системы контроля качества являются участие персонала в создании систем и критериев оценки качества, создание системы самоконтроля обслуживающего персонала и непосредственное участие клиента в оценке качества оказанной услуги. Последнее позволяет наиболее объективно оценить, насколько хорошо работники предприятия обслуживают клиента, а первые два - дают руководителю уверенность в том, что его подчиненные осознают важность их работы и сознательно подходят к исполнению своих обязанностей.

Еще одним способом контроля качества сервиса является мониторинг степени удовлетворенности потребителей. Маркетологи проводят исследование с помощью анкетирования, в котором потребителям необходимо, как правило, ответить на несколько вопросов: насколько они удовлетворены, порекомендуют ли они услуги данного туристического предприятия своим зна- комым и останутся ли они привержены данному туристическому предприятию в будущем.

Ответы на эти вопросы позволят руководству организации быстро и понятно оценить уровень качества оказания услуг в их предприятии и предпринять соответствующие корректирующие меры.

Таким образом, управление качеством туристической услуги формируется из следующих составляющих:

- Определение потребностей и ожиданий потребителей,

- Стандартизация процессов,

- Обеспечение оптимальных условий и мотивации для персонала,

- Контроль качества обслуживания со стороны потребителя, работника и руководства предприятия.

Такие меры позволят организации постоянно совершенствовать качество обслуживания потребителей и, как следствие, удерживать долю рынка.

Общественные объединения предлагают продлить действие программы субсидирования внутреннего туризма на 2021 год. Реализация туров на сумму более 1 млрд рублей с 20 по 28 августа 2020 года по программе кэшбека в сфере туризма запущенной Ростуризмом и АО "Национальной система платежных карт" свидетельствует об ее исключительной востребованности.

Для повышения предпринимательской активности в туристической сфере в межсезонье, когда больше половины туров являются экскурсионными, необходимо:

- предоставить возможность туристам планировать поездку заранее, хотя бы за 4-5 недель.

- сократить минимальную продолжительность поездки. Необходимо снижать стоимость поездки, участвующей в кэшбэке. Пересмотреть требование «одна карта, один турист, одна поездка».

- ввиду того, что в Крым 65\% туристов едут на своем транспорте необходимо изменить требование на зимний сезон и межсезонье о наличии в туре транспортных услуг.

Темпы развития сферы туристических услуг увеличиваются с каждым годом. Появление новых компаний, реализующих качественно новые типы услуг на рынке туризма, способствует усилению конкурентной борьбы. Главным фактором, влияющим на конкурентные позиции туристического предприятия, будет качество оказания туристических услуг. Вне зависимости от прочих факторов конкуренции предприятие сможет стабильно привлекать новых и удерживать старых клиентов при постоянном совершенствовании качества сервиса. 


\section{ЛИТЕРАТУРА}

1. К Кенофонтова Т.Ю. Методологические аспекты использования нематериальных активов в процессе управления конкурентоспособностью производственных предприятий - монография / Федеральное государственное бюджетное образовательное учреждение высшего профессионального образования "Санкт-Петербургский государственный инженерно-экономический университет". Санкт-Петербург, 2012.

2. К Кенофонтова Т.Ю., Мардас А.Н., Гуляева 0.А., Мардас Д.А. В поисках технологических прорывов: почему в России мало успешных стартапов? / В сборнике: Умные технологии в современном мире. Материалы юбилейной всероссийской научно-практической конференции, посвященной 75-летию Южно-Уральского государственного университета. Под редакцией И.А. Баева. 2018.

3. Мардас А.Н., Кадиев И.Г., Гуляева 0.А. Мотивационная координация как основа управления инвестиционно-инновационной деятельностью в хозяйственном комплексе региона и принципы ее реализации / Инновации. 2012. № 8 (166).

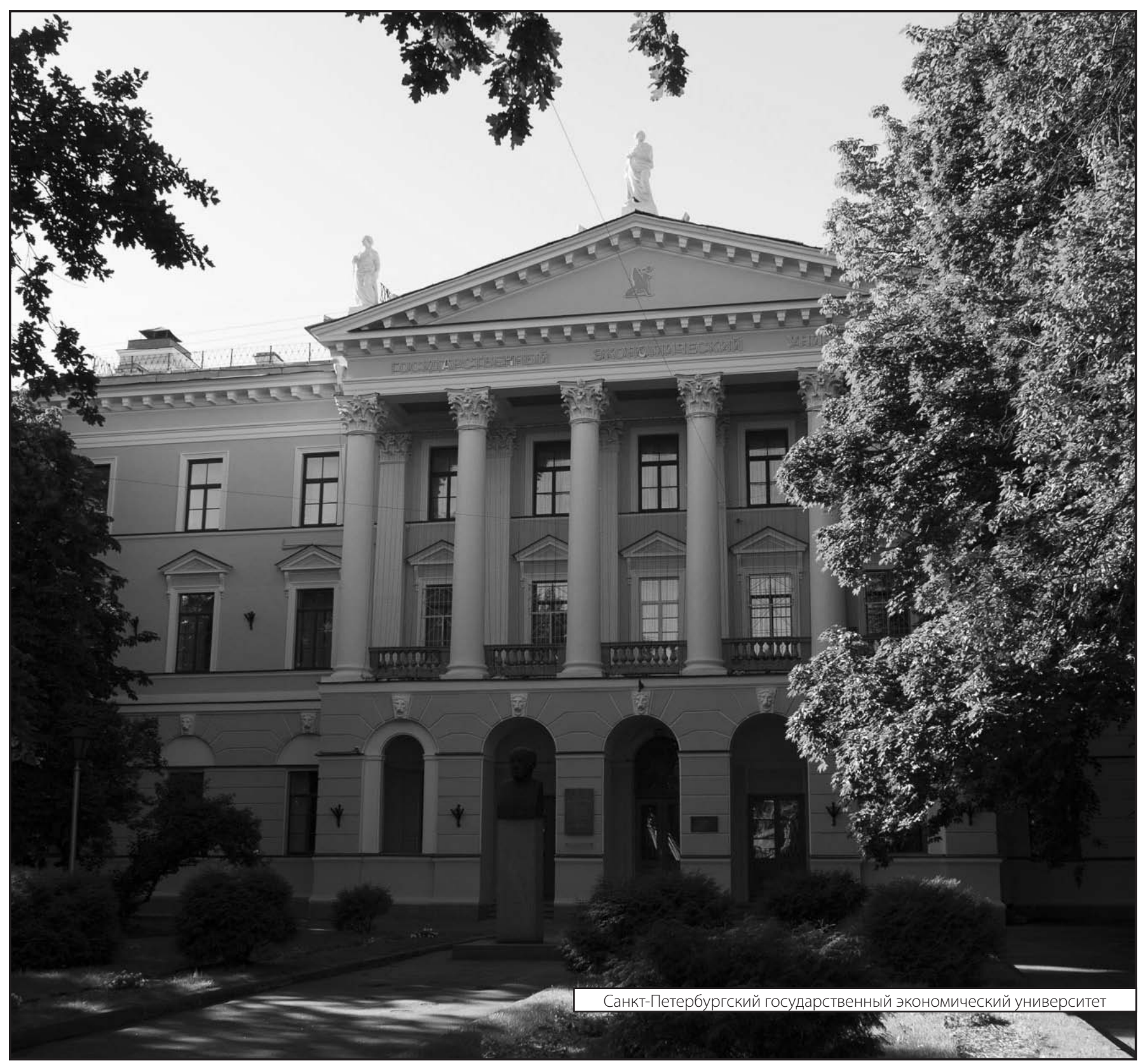

